\title{
JAK2/STAT3 Signaling Pathway Plays a Key Role in Nicotine Mediated Neuroinflammation Suppression in an Ischemic Rat Model
}

\section{Qi Wang}

The First Hospital of China Medical University: The First Affiliated Hospital of China Medical University

\section{Tingting Han}

Chifeng Municipal Hospital

\section{Ruihe Lai}

Nanjing Drum Tower Hospital: Nanjing University Medical School Affiliated Nanjing Drum Tower Hospital

\section{Dalong Zhang}

The First Hospital of China Medical University: The First Affiliated Hospital of China Medical University

Yao Diao

The First Hospital of China Medical University: The First Affiliated Hospital of China Medical University

\section{Yong Du}

Royal Marsden Hospital NHS Trust: Royal Marsden NHS Foundation Trust

Yafu Yin ( $D$ yinyf-2001@163.com)

Shanghai Jiaotong University School of Medicine Xinhua Hospital https://orcid.org/0000-0002-4818-6655

\section{Research Article}

Keywords: cognitive impairment, a4ß2 nicotine acetylcholine receptor, nicotine, JAK2-STAT3

Posted Date: February 23rd, 2021

DOI: https://doi.org/10.21203/rs.3.rs-222193/v1

License: (c) (i) This work is licensed under a Creative Commons Attribution 4.0 International License. Read Full License 


\section{Abstract}

\section{Background}

To explore the mechanism of nicotine mediated improvement of cognitive impairment in an established ischemic rat model.

Methods

Endothelin-1 (ET-1) was injected into the left thalamic region in adult male Sprague-Dawley (SD) rats to establish ischemia model. 6 groups of rats ( 6 rats in each group) were then treated with nicotine, nicotine+DHßE, DHBE, AG490, nicotine +AG490 and saline respectively via intraperitoneal injection for 9 days. Another sham operation group was treated with saline as above. Morris Water Maze (MWM) test was performed for 6 consecutive days starting on the 4th day after operation to detect the cognitive function of rats in each group. 2-[18F]-A-85380 microPET imaging was performed on day 10 to evaluate the changes of $a_{4} \beta_{2}$ nAChRs in different brain regions of rats. Real-time PCR and Western blot were used to detect the amount of $a_{4} \beta_{2} n A C h R s, ~ J A K 2$, STAT3 and inflammatory factors in thalamus of rats in each group.

Results

The results of MWM test showed the spatial learning and memory abilities of rats in the nicotine and sham operation groups were significantly better than the saline treating group in this ischemic rat model $(p<0.05)$. There was no significant difference in other groups ( $p>0.05$ ). MicroPET imaging showed more uptake of $2-\left[{ }^{18} \mathrm{~F}\right]-\mathrm{A}-85380$ in the nicotine, nicotine $+\mathrm{AG} 490$ and sham operation groups than in saline treating group, while there was no significant difference found in other groups $(p>0.05)$. The expression of $a_{4^{-}}$ and $\beta_{2}$-nAChR in nicotine, nicotine+AG490 and sham operation groups was significantly higher than the saline treating group $(p<0.05)$. In the nicotine group, the expression of p-JAK2 and p-STAT3 in left thalamus of rats was significantly higher than the saline treating group $(p<0.05)$, and the expression of IL-1 $\beta$ and IL- 6 protein was found to be lower than the saline treating group $(p<0.05)$. While the expression of p-JAK2, p-STAT3 and inflammatory factors was not significantly different in all the other groups $(p>0.05)$.

Conclusion

The study suggests nicotine inhibits the expression of inflammatory factors by activating $a_{4} \beta_{2} n A C h R s$ through the activation of JAK2-STAT3 signaling pathway to improve cognitive impairment in ischemic rats.

\section{Introduction}

Vascular cognitive impairment $(\mathrm{VCl})$ is a kind of syndrome mainly caused by cerebral vascular disease, ranging from mild cognitive impairment to dementia. It is the second leading cause of dementia after Alzheimer's disease[1]. Studies showed that nicotine can play an important role in the protection of cognitive function[2-5]. Nicotine is an agonist of neuronal nicotinic acetylcholine receptors (nAChRs), which are composed of five subunits arranged around a water-filled pore. The most abundant nAChR subtypes in the mammalian brain are heteromeric $a_{4} \beta_{2} n A C h R s$ and homomeric $a_{7} n A C h R s$, and $a_{4} \beta_{2}$ is the most abundant subtype in the CNS and with high affinity for nicotine [6-8]. Histopathological studies have shown that under ischemic conditions, inflammation caused by microglia overactivation can destruct the blood-brain barrier, cause brain damage and prompt the occurrence and development of VCI[9-12]. Our prior studies have confirmed that the chronic ischemic cognitive dysfunction was correlated with the decrease of $a_{4} \beta_{2} n A C h R s[13]$, and nicotine played a role in inhibiting the inflammatory factors, which contributes to improving cognitive impairment by activating $a_{4} \beta_{2}$ nAChRs in ischemic rats[14]. How $a_{4} \beta_{2}$ nAChRs activated by nicotine acts on inflammatory factors remains uncertain.

The JAK-STAT signalling pathway is known to be a chain of interactions between proteins in a cell, and is involved in processes such as immunity, cell division, cell death and tumor formation. Abnormal activation of JAK2-STAT3 signaling pathway is often closely related to the occurrence, development and prognosis of inflammatory diseases, tumors, autoimmune diseases, etc.[1517]. Studies have shown that JAK2 and STAT3 can regulate the plasticity of hippocampal synapses and are closely related to learning and memory[18]. In this study, we aimed to explore the relationship between JAK2-STAT3 signaling pathway and $a_{4} \beta_{2}$ 
nAChRs activation induced by nicotine in ischemic rats. Nicotine, $D H \beta E$ (the most potent competitive antagonist of $a_{4} \beta_{2}$ nAChRs $[19,20]$ ) and AG490 (a specific JAK2/STAT3 blocker[21, 22]) were adopted for intervention treatment, and 2-[18 F]-A-85380 micro-PET imaging was performed for detecting $a_{4} \beta_{2} n A C h R s[23]$ in ischemic rats in this study.

\section{Materials And Methods}

All animal experiments were approved by the Ethics Committee of The First Hospital of China Medical University, and all experiments were performed in accordance with relevant guidelines and regulations.

\section{Laboratory Animals and Groups}

Forty-seven male Sprague-Dawley (SD) rats, about 8 weeks old, weighing $250 \pm 20$ g, were ordered (China Medical University animal laboratory, SYXK (Liao)2008-0005, Shenyang, China) to SPF animal laboratory. Before the experiment, the rats were fed freely and given $12 \mathrm{~h}-12 \mathrm{~h}$ light-dark cycle.

Ischemic models were established by injecting ET-1 (MERCK, USA) into the left thalamus, the steps in detail were described in the previous study[14]. The model of sham operation group was established: the specific method was the same as above, but ET-1 was replaced by normal saline. On the first day after operation, nicotine (Sigma Aldrich), DHBE (ApexBio, USA), AG490 (SELLECK, USA) or saline were administered according to different grouping: nicotine group (nicotine, $1.5 \mathrm{mg} / \mathrm{kg} / \mathrm{d}$ ), nicotine + DH $\beta E$ group (nicotine, $1.5 \mathrm{mg} / \mathrm{kg} / \mathrm{d} ; \mathrm{DH} \beta E, 3 \mathrm{mg} / \mathrm{kg} / \mathrm{d}$ ), DHßE group (DHßE, 3mg/kg/d), nicotine + AG490 group (nicotine, 1.5mg/kg/d; AG490, $3 \mathrm{mg} / \mathrm{kg} / \mathrm{d}$ ), AG490 group (AG490, $3 \mathrm{mg} / \mathrm{kg} / \mathrm{d}$ ), ischemia group (saline, $0.8 \mathrm{ml} / \mathrm{kg} / \mathrm{d}$ ) and sham operation group (saline, 0.8 $\mathrm{ml} / \mathrm{kg} / \mathrm{d}$ ). Each group consisted of 6 rats and all 42 rats received the intervention by intraperitoneal injection for nine consecutive days.

The other 3 SD rats did not receive any intervention neither operation nor drugs and they were used as a control group for PCR test. Another two rats were sacrificed 24 hours after surgery only for histological analysis with HE staining to make sure the success of ischemic model (Fig. 1), one from the sham operation group, the other from ischemia group.

\section{Morris Water maze experiment}

On the fourth day of drug intervention, Morris water maze (MWM) (endocrinology laboratory, China Medical University) test was performed to test the spatial learning and memory ability of rats. Rats of different groups were subjected to six consecutive days of experiments, which were divided into the following two parts:

Directional navigation experiment: the experiment lasted for 5 days. On the first day, a directional navigation program was set up. Rats were put into the pool from any two quadrants to familiarize themselves with the water maze environment. Platform was placed in the center of a quadrant of the pool. The training tests were conducted at the same time every day for the next four days. The software automatically recorded the swimming trajectory and swimming time of each rat in the pool.

The space exploration experiment: on the sixth day of the experiment, after setting up the space exploration program, the platform was removed, and the rats were put into any quadrant (except the target quadrant where the original platform was located). The software automatically recorded and analyzed the times that the rats crossed the target quadrant and the activity time in target quadrant in 120 seconds.

\section{2-[ $\left.{ }^{18} \mathrm{~F}\right]-\mathrm{A}-85380$ Micro PET imaging}

After the MWM test, rats in each group underwent 2-[18 F]-A-85380 micro-PET imaging (Shandong Madic Technology Co., Ltd, China) on the 6th day of MWM. 2-[18 F]-A-85380 was synthesized according to the previous report [24]. $37 \mathrm{MBq} 2-\left[{ }^{18} \mathrm{~F}\right]-\mathrm{A}-85380$ was injected by tail vein of rats. Head scan was performed for 10 minutes after 120 minutes.

Quantitative analysis: Drawing ROI was based on standard rat brain atlas by Paxinos[25]. The cerebellum was used as the reference area, and the ratio of the average SUV $\left(S_{U} V_{\text {ave }}\right)$ in each area to the SUV ave of the cerebellum was calculated. The distribution of $2-\left[{ }^{18} \mathrm{~F}\right]-\mathrm{A}-85380$ in the left thalamus and the whole brain of each group was quantitatively analyzed.

Page $3 / 14$ 


\title{
Real-Time PCR Detection of Receptor Subunits of nAChRs
}

The RNA extraction was performed firstly, followed by the reverse transcription synthesis of cDNA. The mixture was homogenized and the sample was placed on a reverse transcription instrument at $37^{\circ} \mathrm{C}, 15 \mathrm{~min} ; 85^{\circ} \mathrm{C}, 5 \mathrm{~s} ; 4^{\circ} \mathrm{C}, 10 \mathrm{~min}$. Real-time PCR amplification curve and dissolution curve were confirmed after the reaction, and the CT value of the sample was calculated automatically by software. RNAiso plus (N0.9108/9109), SYBR Premix Ex Taq II (RR820A), Prime Script RT Reagent Kit (\#RR037A) were purchased from TaKaRa company, Japan. Primers used for the study were as follows:

$a_{4}$ nAChR: F: 5'-ATGGATGAAACCTACCTGATGAGCA-3'

\section{R: 5'-GCTGGGGGTTGTAGCAGGCAC-3'}

$\beta_{2}$ nAChR: F: 5'-CGGGAAGCAGTGGATGGCGTA-3'

\section{R: 5'-GTCCTCCCTCACACTCTGGTCATCA-3'}

\author{
ß-Actin: F: 5'-CATCCTGCGTCTGGACCTGG-3'
}

R: 5'-TAATGTCACGCACGATTTCC-3'.

\section{Western blot}

The left thalamic tissue was taken and stored in an Eppendorf tube in a refrigerator at $-80^{\circ} \mathrm{C}$. The tissues of each group were added with $1 \mathrm{ml}$ RIPA buffer and PMSF mixture (RIPA: PMSF = 100:1). After homogenizing on ice by tissue homogenizer, the tissues were placed on ice for 30 minutes, centrifuged, $4^{\circ} \mathrm{C}, 15,000 \mathrm{rpm}$ for $15 \mathrm{~min}$. The supernatant was then taken and stored at $-80^{\circ} \mathrm{C}$. According to BCA protein quantitative standard curve, different samples were adjusted to the same concentration with lysis buffer $\left(3-5 \mu \mathrm{g} / \mu \mathrm{l}\right.$ for each sample). All the samples were denatured by heating at $95^{\circ} \mathrm{C}$ for $10 \mathrm{mins}$, and stored at $-20^{\circ} \mathrm{C}$. Finally, 15-20 $\mu \mathrm{l}$ sample was added into each lane to ensure the same amount of protein. Equal amounts of proteins were fractionated by SDS-PAGE electrophoresis apparatus, transferred to PVDF membranes. Immunoblotting was carried out with antibodies against $\alpha_{4}$-nAChRs(1:500), $\beta_{2}$-nAChRs(1:500), IL-1 $\beta(1: 2000)$, IL-6(1:2000), JAK2(1:1000), STAT3(1:1000), pJAK2(1:1000), p-STAT3(1:2000), $\beta$-actin $(1: 1000)$ at $4^{\circ} \mathrm{C}$ for $24 \mathrm{~h}$. The membranes were incubated with corresponding secondary antibodies at room temperature for $1 \mathrm{~h}$. Western blots were developed by enhanced chemiluminescence detection system. Image Lab software was used for gel electrophoresis image analysis. The gray value of the panel was used for quantitative analysis, and the histogram was obtained to show the protein expression of each group in each index. Quantitative analysis was performed basing on three individual samples preparation following with western bloting.

Primary antibodies $\left(a_{4}-n A C h R\right.$, ab41172; $\beta_{2}-n A C h R$, ab189174; IL-1 $\beta$, ab2105; IL-6, ab9324; p-JAK2, ab32101) were purchased from ABCAM company, USA; Primary antibodies (JAK2, D2E12; STAT3,124H6; p-STAT3, D3A7) were from Cell Signaling Technology, USA; BCA Protein Assay Kit was from Beyotime Biotechnology Research Institute, China; RIPA Lysis Buffer was from Beyotime Biotechnology Research Institute, China; PMSF was from Beijing Solarbio Science \& Technology company, China.

\section{Statistical Analysis}

All statistical analyses were performed using ANOVA of IBM SPSS Statistics. Variance analysis was applied for inter-group comparison and Tukey's method was used for in Multiple Comparison Correction. Shapiro-Wilk test was used to check the normal distribution. At least three individual trials were performed for each experiment and data was represented as mean \pm SD. $p<0.05$ was considered statistically significant. Specific $p$ values were indicated in notes of tables and figures.

\section{Results}

\section{MWM test indicated nicotine improving cognition but blocked by DH $\beta E$ and AG490}

Normality was checked using the Shapiro-Wilk test, which showed that the data fit a normal distribution. We assumed normal distribution since the sample size was too small to test the normality assumption properly. Using variance analysis of repeated 
measurement design data to analyze the latency in directional navigation experiment, the escape latency of rats in each group decreased with the increase of experimental days, but the interaction between time and groups had no statistical significance $(\mathrm{F}=0.058, p=0.99>0.01)$, indicating that the time factors did not vary with the grouping. There were significant differences in escape latency between different groups $(F=4.942, p=0.01<0.05)$ (Table 1$)$. The escape latency of rats in the nicotine group and the sham operation group was shorter than ischemic rats treated with saline only, and the difference was statistically significant $(p<0.05)$ (Table 1, Fig. 2). There was no significant difference in escape latency between rats in the nicotine+DH $\beta E$ group, DH $\beta E$ group, nicotine+AG490 group and AG490 group compared with ischemic rats given saline $(p>0.05)$.

The results of space exploration experiment: the number of times that the rats crossed the target quadrant and the activity time in the target quadrant area were listed in Table 1. There were significant differences in the number of times crossing the target quadrant and the activity time in target quadrant in the nicotine group and sham operation group compared with the ischemia group ( $p<0.05)$. There was no significant difference in the nicotine+DHßE group, DH $\beta E$ group, nicotine+AG490 group and AG490 group compared with the ischemia group $(p>0.05)$, indicating that nicotine improved the cognitive function of ischemic rats, but the effect was blocked by DHßE and AG490.

\section{Micro-PET imaging showed nicotine up-regulating $a_{4} \beta_{2}$ nAChRs was blocked by DH $\beta E$ not AG490}

The uptake of 2-[ $\left.{ }^{18} \mathrm{~F}\right]-\mathrm{A}-85380$ in left thalamus and whole brain of rats in the nicotine group, nicotine+AG490 group and sham operation group was significantly higher than ischemic rats treated with saline only $(p<0.05)$ (Fig. 3, Table 2). There was no significant difference between the nicotine+DH$\beta E$ group, the $D H \beta E$ group and the AG490 group compared with the ischemia group $(p>0.05)$.

\section{Real-time PCR indicated nicotine upregulating $\alpha_{4} \beta_{2}$ nAChRs blocked by DHßE not AG490}

Real-time PCR was performed to determine the relative expression of receptor subunits $a_{4}$ and $\beta_{2} n A C h R$ in the left thalamus of rats. Three samples in each group were detected, and three technical replications for each sample were performed. The average CT values were obtained by amplifying $\beta$-actin and $a_{4}, \beta_{2}$-nAChR respectively. The results (Table 3, Fig 4) showed that the expression of $a_{4} n A C h R$ and $\beta_{2} n A C h R$ mRNA were lower in ischemic rats given saline (ischemia group) than in the sham operation group $(0.51 \pm 0.04,0.68 \pm 0.04)$. The expression of $a_{4} n A C h R$ and $\beta_{2} n A C h R$ mRNA in the left thalamus of rats in nicotine group was significantly higher than rats in ischemia group $(0.75 \pm 0.16, p<0.05 ; 0.86 \pm 0.11, p<0.05)$. The expression levels of $a_{4} n A C h R$ and $\beta_{2}$ nAChR mRNA in left thalamus of rats in nicotine+AG490 group were still significantly higher than ischemic rats given saline $(0.74 \pm 0.07, p<0.05 ; 0.82 \pm 0.03, p<0.05)$, and there was no significant difference between nicotine+AG490 and nicotine groups, suggesting that nicotine could increase the number of $\alpha_{4} n A C h R$ and $\beta_{2} n A C h R$, while AG490 could not block this function. The expression of $a_{4} n A C h R$ and $\beta_{2} n A C h R$ mRNA in left thalamus of nicotine+DHBE group, DH $\beta E$ group and AG490 group was significantly lower than nicotine and nicotine+AG490 groups, but there was no significant difference compared with ischemia group.

\section{Western blot showed nicotine inhibiting inflammation by $a_{4} \beta_{2}$ nAChRs upregulation and activation of JAK2-STAT3 signaling pathway}

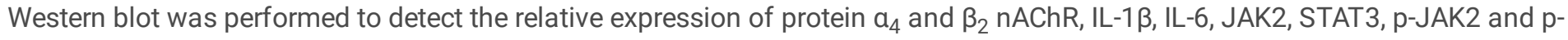
STAT3 in the left thalamus of rats. The internal reference was $\beta$-actin. Three samples were collected from each group, and the expression of each group was obtained by gray level detection. Western blot results (Table 4, Fig 5) showed that the expression of $a_{4} n A C h R$ and $\beta_{2} n A C h R$ protein in nicotine and nicotine+AG490 groups was significantly higher than ischemic rats treated with saline only $(1.91 \pm 0.18, p<0.05 ; 2.05 \pm 0.12, p<0.05 ; 1.88 \pm 0.12, p<0.05 ; 1.91 \pm 0.03, p<0.05)$. The expression levels of $p-J A K 2$ and $p-$ STAT3 protein in nicotine group were significantly higher than ischemic rats given saline $(0.95 \pm 0.03, p<0.05 ; 1.12 \pm 0.02, p<0.05)$. The expression of p-JAK2 and p-STAT3 protein in nicotine+DH 3 group, nicotine+AG490 group and AG490 group was not significantly different from rats in ischemia group. The expression of IL-1 $\beta$ and IL-6 protein in left thalamus of rats in nicotine group was lower than ischemia group $(0.67 \pm 0.02, p<0.05 ; 1.17 \pm 0.03, p<0.05)$, while the relative expression of inflammatory factors in nicotine+DH $\beta E$ group, nicotine+AG490 group and AG490 group was not significantly different from ischemia group $(p>0.05)$. These results suggested that the inflammatory response in the brain was enhanced after thalamic ischemia in rats. After nicotine 
intervention, $a_{4} \beta_{2} n A C h R s$ in the brain was up-regulated, and JAK2-STAT3 signaling pathway was then activated by $a_{4} \beta_{2} n A C h R s$, thus reducing the expression of inflammatory factors in the brain.

\section{Discussion}

Our previous studies $[13,14]$ showed that the cognitive impairment in ischemic rats induced by ET-1 was correlated with the impairment of $a_{4} \beta_{2} n A C h R s$. Appropriate dose of nicotine could improve the learning and memory ability of ischemic rats. This improvement of cognition was related to the increased density of $a_{4} \beta_{2} n A C h R s$ in the thalamus and whole brain after nicotine intervention[14]. When thalamic ischemia happened, the inflammatory response in rat brain was elevated. Nicotine further inhibited the expression of inflammatory factors by activating the $\alpha_{4} \beta_{2} n A C h R s$, thereby improving cognitive function[14]. Inflammatory reaction after cerebral ischemia injury is mainly manifested by infiltration of peripheral blood leukocytes in brain parenchyma and up-regulation of the intrinsic glial cells activation (microglia and astrocytes)[26]. In the early stage of cerebral infarction, it can trigger a series of inflammatory cascade reactions and prompt the excessive secretion of local inflammatory cytokines and chemokines, such as selectin, TNF- $a, \mathrm{IL}-1, \mathrm{IL}-6, \mathrm{IL}-1 \beta$, nitric oxide (NO), cyclooxygenase-2 (COX-2), inducible nitric oxide synthase (iNOS), etc.[26]. The leukocytes were attracted to vascular endothelium and aggregated in ischemic area, thus activating the secondary inflammatory reaction downstream and forming a vicious circle[27, 28]. At the same time, 2-4 hours after the early stage of cerebral ischemia, microglia were activated by inflammatory cytokines, which further aggravated brain injury[29].

Nowadays, studies have shown that neuroinflammation is closely related to cognitive impairment [30-32], especially the activation of microglia is the key point leading to neuroinflammation. Anti-inflammatory therapy has also been used to treat cognitive impairment. Guan Y.Z. [33] et al. found that nicotine could inhibit the release of inflammatory factors by inhibiting the increment of microglia after nicotine intervention.

JAK-STAT signaling pathway is an important target of a variety of human diseases. In the central nervous system, this signaling pathway is closely related to brain inflammation and the survival and development of neurons/glial cells[34]. It has been found that JAK2 and STAT3 can regulate synaptic plasticity in hippocampus, which is closely related to learning and memory. Therefore, more and more attention has been paid to the role of JAK2-STAT3 signaling pathway in central nervous system diseases, including Alzheimer's disease, depression and anxiety disorders. AG490 is a specific antagonist of JAK2 and one of the PTK inhibitors[21]. As a specific blocker of JAK2-STAT3 signaling pathway, AG490 inhibits the phosphorylation of JAK2 and STAT3 downstream of JAK2, thereby blocking cell signal transduction $[35,36]$.

In this study, we established a rat model of ischemic cognitive impairment induced by ET-1, and explored the relationship between neuroprotective mechanism of nicotine, $a_{4} \beta_{2} n A C h R s$, inflammation and JAK2-STAT3 signaling pathway. MWM test showed that the learning and memory ability was significantly improved by nicotine intervention, but no significant improvement was observed when nicotine was given with $D H \beta E$ together, or with AG490 together. $2-\left[{ }^{18} \mathrm{~F}\right]-\mathrm{A}-85380$ PET imaging showed that $a_{4} \beta_{2} n A C h R s$ increased significantly in rats brain when nicotine was given alone, or with AG490 together. The study demonstrated that nicotine intervention increased the density of $a_{4} \beta_{2} n A C h R s$ and improved cognitive impairment, but this effect would be blocked by AG490, while receptors were still upregulated. Essentially, when JAK2-STAT3 signaling pathway was blocked, nicotine could only upregulate the expression of $a_{4} \beta_{2} n A C h R s$, but not improve the cognitive function. The results were further confirmed by PCR and Western blot analysis. Our findings suggest that nicotine can improve ischemic cognitive impairment by up-regulating $a_{4} \beta_{2}$ nAChRs, thereby activating JAK2-STAT3 signaling pathway to reduce inflammatory factors. Therefore, $a_{4} \beta_{2}$ nAChRs-JAK2/STAT3 signaling pathway plays an important role in inhibiting neuroinflammation in ischemic rats.

One of the limitations in this study is that immunofluorescence co-staining assay was not performed to provide more direct evidence to confirm if nicotine acts via $a_{4} \beta_{2}$ nAChRs in immune cells (microglia, astrocyte) or in neurons, for some study demonstrated the overexpression of $a_{4} \beta_{2} n A C h R s$ in both microglia and astrocytes from days 7-28 after experimental ischemic stroke[37]. The reaction of JAK2-STAT3 in immune cells taken from the ischemic region also needs to be investigated further. Another area needs to be further explored is that this study could not confirm the effect of JAK2-STAT3 activating by $a_{4} \beta_{2}$ nAChRs was direct or indirect, for example, where nicotine affects the expression of another protein that then activates the JAK2/STAT3 pathway. 


\section{Conclusion}

In an established ischemic rats model, nicotine could activate JAK2-STAT3 signaling pathway by up-regulating $a_{4} \beta_{2} n A C h R s$ to inhibit the expression of inflammatory factors, thereby improving rats cognitive function.

\section{Declarations}

\section{Ethics approval and consent to participate}

Animal care and all experimental procedures were performed in accordance with the Guideline for the Care and Use of Laboratory Animals. All animals received humane care. Study protocols complied with the institution's guidelines and were approved by the Ethics Committee of The First Hospital of China Medical University.

\section{Consent for publication}

All authors have read and agreed to the published version of the manuscript.

\section{Availability of data and material}

The authors confrm that the data supporting the findings of this study are available within the article.

\section{Competing interests}

The authors declare no competing interests.

\section{Funding}

This study was funded by the National Natural Science Foundation of China (No.81671717, 81974270) and Shanghai Pujiang Talent Program D (2019PJD032) .

\section{Authors' contributions}

Y. Y.: Conceived and designed the experiments; W.Q.: Performed the experiments, the analysis and interpretation of data, and drafted the main manuscript text; H.T. and L.R.: Assisted in expreiments and data analysis; Z.D.: Synthesized the tracer of 2-[18F]A-85380; D.Y. (Yao Diao): Guided the specific implementation of the experiment; D.Y. (Yong Du): Critical revision of the manuscript.

\section{Acknowledgements}

None.

\section{References}

1. Valenti R, Del Bene A, Poggesi A, Ginestroni A, Salvadori E, Pracucci G, et al. Cerebral microbleeds in patients with mild cognitive impairment and small vessel disease: The Vascular Mild Cognitive Impairment (VMCl)-Tuscany study. J Neurol Sci. 2016;368:195-202.

2. Araya JA, Ramirez AE, Figueroa-Aroca D, Sotes GJ, Perez C, Becerra J, et al. Modulation of neuronal nicotinic receptor by quinolizidine alkaloids causes neuroprotection on a cellular Alzheimer model. J Alzheimers Dis. 2014;42:143-55.

3. Vieira-Brock PL, McFadden LM, Nielsen SM, Smith MD, Hanson GR and Fleckenstein AE. Nicotine Administration Attenuates Methamphetamine-Induced Novel Object Recognition Deficits. Int J Neuropsychopharmacol. 2015;18:

4. Ciobica A, Padurariu M and Hritcu L. The effects of short-term nicotine administration on behavioral and oxidative stress deficiencies induced in a rat model of Parkinson's disease. Psychiatr Danub. 2012;24:194-205.

5. Jucaite A, Ohd J, Potter AS, Jaeger J, Karlsson P, Hannesdottir K, et al. A randomized, double-blind, placebo-controlled crossover study of alpha4beta 2* nicotinic acetylcholine receptor agonist AZD1446 (TC-6683) in adults with attentiondeficit/hyperactivity disorder. Psychopharmacology (Berl). 2014;231:1251-65. 
6. Zoli M, Pucci S, Vilella A and Gotti C. Neuronal and Extraneuronal Nicotinic Acetylcholine Receptors. Curr Neuropharmacol. 2018;16:338-349.

7. Paterson D and Nordberg A. Neuronal nicotinic receptors in the human brain. Prog Neurobiol. 2000;61:75-111.

8. Dani JA. Neuronal Nicotinic Acetylcholine Receptor Structure and Function and Response to Nicotine. Int Rev Neurobiol. 2015;124:3-19.

9. Ding YS, Fowler JS, Logan J, Wang GJ, Telang F, Garza V, et al. 6-[18F]Fluoro-A-85380, a new PET tracer for the nicotinic acetylcholine receptor: studies in the human brain and in vivo demonstration of specific binding in white matter. Synapse. 2004;53:184-9.

10. Lotfipour S, Mandelkern M and Brody AL. Quantitative Molecular Imaging of Neuronal Nicotinic Acetylcholine Receptors in the Human Brain with A-85380 Radiotracers. Curr Med Imaging Rev. 2011;7:107-112.

11. Kant R, Constantinescu CC, Parekh P, Pandey SK, Pan ML, Easwaramoorthy B, et al. Evaluation of F-nifene binding to alpha4beta2 nicotinic receptors in the rat brain using microPET imaging. EJNMMI Res. 2011;1:

12. Jiang Y, Yin Y and Li Y. Clinical research progress of fluoride and iodide 3-[2(S) -azacyclobutane methoxy] pyridine. Chinese Journal of Nuclear Medicine and Molecular Imaging. 2015;35:322-5.

13. Jiang Y, Diao Y, Yin Y, Huang L, Mo Y, Zhang D, et al. The Quantitative Analysis of 2-[18F]-A-85380 nAChRs Micro-PET Brain Imaging in Chronic Ischemic Rats with Cognitive Dysfunction in Vivo. Journal of Isotopes. 2017;30:110-8.

14. Han T, Wang Q, Lai R, Zhang D, Diao Y and Yin Y. Nicotine Induced Neurocognitive Protection and Anti-inflammation Effect by Activating alpha 4beta 2 Nicotinic Acetylcholine Receptors in Ischemic Rats. Nicotine Tob Res. 2020;22:919-924.

15. Wu Y, Xu J, Xu J, Zheng W, Chen Q and Jiao D. Study on the mechanism of JAK2/STAT3 signaling pathway-mediated inflammatory reaction after cerebral ischemia. Mol Med Rep. 2018;17:5007-5012.

16. Chen J, Wang S, Su J, Chu G, You H, Chen Z, et al. Interleukin-32alpha inactivates JAK2/STAT3 signaling and reverses interleukin-6-induced epithelial-mesenchymal transition, invasion, and metastasis in pancreatic cancer cells. Onco Targets Ther. 2016;9:4225-37.

17. Qin K, Chen K, Zhao W, Zhao X, Luo J, Wang Q, et al. Methotrexate Combined with 4-Hydroperoxycyclophosphamide Downregulates Multidrug-Resistance P-Glycoprotein Expression Induced by Methotrexate in Rheumatoid Arthritis FibroblastLike Synoviocytes via the JAK2/STAT3 Pathway. J Immunol Res. 2018;2018:3619320.

18. Nicolas CS, Peineau S, Amici M, Csaba Z, Fafouri A, Javalet C, et al. The Jak/STAT pathway is involved in synaptic plasticity. Neuron. 2012;73:374-90.

19. Kutlu MG, Tumolo JM, Cann C and Gould TJ. Differential effects of alpha4beta2 nicotinic receptor antagonists and partialagonists on contextual fear extinction in male C57BL/6 mice. Psychopharmacology (Berl). 2018;235:1211-1219.

20. Lewis AS, Mineur YS, Smith PH, Cahuzac ELM and Picciotto MR. Modulation of aggressive behavior in mice by nicotinic receptor subtypes. Biochem Pharmacol. 2015;97:488-497.

21. Seo IA, Lee HK, Shin YK, Lee SH, Seo SY, Park JW, et al. Janus Kinase 2 Inhibitor AG490 Inhibits the STAT3 Signaling Pathway by Suppressing Protein Translation of gp130. Korean J Physiol Pharmacol. 2009;13:131-8.

22. Donegan JJ, Girotti M, Weinberg MS and Morilak DA. A novel role for brain interleukin-6: facilitation of cognitive flexibility in rat orbitofrontal cortex. J Neurosci. 2014;34:953-62.

23. Mo YX, Yin YF and Li YM. Neural nAChRs PET imaging probes. Nucl Med Commun. 2014;35:135-43.

24. Huang L, Diao Y, Yin Y, Zhang D, Mo Y and Li Y. Radiosynthesis of 2-[18F]-A-85380 and its biodistribution in mice. Journal of China Medical University. 2013;42:777-780.

25. Paxinos $G$ and Watson C. The rat brain in stereotaxic coordinates. 6th. Academic Press; 2007.

26. Petrovic-Djergovic D, Goonewardena SN and Pinsky DJ. Inflammatory Disequilibrium in Stroke. Circ Res. 2016;119:142-58.

27. Edwards DN and Bix GJ. The Inflammatory Response After Ischemic Stroke: Targeting beta2 and beta1 Integrins. Front Neurosci. 2019;13:540.

28. Anrather J and ladecola C. Inflammation and Stroke: An Overview. Neurotherapeutics. 2016;13:661-670.

29. Colonna M and Butovsky O. Microglia Function in the Central Nervous System During Health and Neurodegeneration. Annu Rev Immunol. 2017;35:441-468. 
30. Wei P, Liu Q, Li D, Zheng Q, Zhou J and Li J. Acute nicotine treatment attenuates lipopolysaccharide-induced cognitive dysfunction by increasing BDNF expression and inhibiting neuroinflammation in the rat hippocampus. Neurosci Lett. 2015;604:161-6.

31. Osso LA and Chan JR. Astrocytes Underlie Neuroinflammatory Memory Impairment. Cell. 2015;163:1574-6.

32. Rehman SU, Shah SA, Ali T, Chung JI and Kim MO. Anthocyanins Reversed D-Galactose-Induced Oxidative Stress and Neuroinflammation Mediated Cognitive Impairment in Adult Rats. Mol Neurobiol. 2017;54:255-271.

33. Guan YZ, Jin XD, Guan LX, Yan HC, Wang P, Gong Z, et al. Nicotine inhibits microglial proliferation and is neuroprotective in global ischemia rats. Mol Neurobiol. 2015;51:1480-8.

34. Yu L, Chen C, Wang LF, Kuang X, Liu K, Zhang H, et al. Neuroprotective effect of kaempferol glycosides against brain injury and neuroinflammation by inhibiting the activation of NF-kappaB and STAT3 in transient focal stroke. PLoS One. 2013;8:e55839.

35. Arango-Davila CA, Vera A, Londono AC, Echeverri AF, Canas F, Cardozo CF, et al. Soluble or soluble/membrane TNF-alpha inhibitors protect the brain from focal ischemic injury in rats. Int J Neurosci. 2015;125:936-40.

36. Park JS, Lee J, Lim MA, Kim EK, Kim SM, Ryu JG, et al. JAK2-STAT3 blockade by AG490 suppresses autoimmune arthritis in mice via reciprocal regulation of regulatory T Cells and Th17 cells. J Immunol. 2014;192:4417-24.

37. Martin A, Szczupak B, Gomez-Vallejo V, Domercq M, Cano A, Padro D, et al. In vivo PET imaging of the alpha4beta2 nicotinic acetylcholine receptor as a marker for brain inflammation after cerebral ischemia. J Neurosci. 2015;35:5998-6009.

\section{Tables}

Table 1 Results of MWM test in all groups

\begin{tabular}{|c|c|c|c|c|c|c|c|}
\hline \multirow[t]{2}{*}{ Groups } & \multirow[t]{2}{*}{ Number } & \multicolumn{4}{|c|}{ Escape latency(seconds) } & \multirow{2}{*}{\multicolumn{2}{|c|}{$\begin{array}{l}\text { Times crossing } \\
\text { target } \\
\text { target quadrant } \\
\text { quadrant(s) }\end{array}$}} \\
\hline & & $2^{\text {nd }}$ day & $3^{\text {rd }}$ day & $4^{\text {th }}$ day & $5^{\text {th }}$ day & & \\
\hline ischemia group & 6 & $84.04 \pm 44.10$ & $78.96 \pm 44.93$ & $73.46 \pm 42.00$ & $60.50 \pm 42.88$ & $2.33 \pm 0.94$ & $27.85 \pm 13.32$ \\
\hline nicotine group & 6 & $50.67 \pm 37.91^{*}$ & $41.46 \pm 37.38 *$ & $35.38 \pm 30.11^{\star}$ & $26.46 \pm 24.93^{\star}$ & $5.50 \pm 2.06^{\star}$ & $52.51 \pm 7.56^{\star}$ \\
\hline $\begin{array}{l}\text { nicotine + DH } \beta E \\
\text { group }\end{array}$ & 6 & $83.67 \pm 44.69$ & $72.17 \pm 45.98$ & $61.17 \pm 42.62$ & $48.83 \pm 37.19$ & $3.17 \pm 2.41$ & $30.18 \pm 8.34$ \\
\hline $\mathrm{DH} \beta \mathrm{E}$ group & 6 & $82.67 \pm 39.84$ & $76.51 \pm 39.40$ & $65.59 \pm 40.90$ & $53.78 \pm 33.44$ & $3.21 \pm 2.54$ & $33.23 \pm 5.09$ \\
\hline $\begin{array}{l}\text { nicotine }+ \\
\text { AG490 group }\end{array}$ & 6 & $73.04 \pm 41.07$ & $69.33 \pm 47.04$ & $52.75 \pm 39.69$ & $46.92 \pm 39.08$ & $2.67 \pm 1.70$ & $36.57 \pm 11.22$ \\
\hline AG490 group & 6 & $77.38 \pm 41.24$ & $72.42 \pm 43.53$ & $61.54 \pm 44.01$ & $49.83 \pm 33.14$ & $2.83 \pm 1.34$ & $33.71 \pm 6.55$ \\
\hline $\begin{array}{l}\text { sham operation } \\
\text { group }\end{array}$ & 6 & $29.21 \pm 17.85^{\star}$ & $25.67 \pm 24.05^{\star}$ & $19.74 \pm 14.53^{*}$ & $11.20 \pm 9.21^{\star}$ & $5.90 \pm 0.98^{*}$ & $55.35 \pm 11.72^{\star}$ \\
\hline
\end{tabular}

Note: Each group was compared in pairs, only the nicotine group and the sham operation group were statistically significant compared with the ischemia group. *: $p<0.05$ versus the ischemia group.

\section{Table 2 Quantitative analysis of micro-PET imaging}




\begin{tabular}{|c|c|c|}
\hline Groups & $\mathrm{SUV}_{\text {ave left thalamus }} / \mathrm{SUV}$ ave cerebellum & $\mathrm{SUV}_{\text {ave whole brain }} / \mathrm{SUV}$ ave cerebellum \\
\hline ischemic group & $2.38 \pm 0.08$ & $1.60 \pm 0.06$ \\
\hline nicotine group & $2.82 \pm 0.13^{*}$ & $1.73 \pm 0.09 *$ \\
\hline nicotine $+\mathrm{DH} \beta E$ & $2.43 \pm 0.11$ & $1.59 \pm 0.06$ \\
\hline $\mathrm{DH} \beta E$ group & $2.39 \pm 0.15$ & $1.57 \pm 0.08$ \\
\hline nicotine + AG490 & $2.80 \pm 0.06^{\star}$ & $1.76 \pm 0.04^{\star}$ \\
\hline AG490 group & $2.31 \pm 0.04$ & $1.60 \pm 0.04$ \\
\hline sham operation group & $2.75 \pm 0.19 *$ & $1.73 \pm 0.18^{*}$ \\
\hline
\end{tabular}

Note: Each group was compared in pairs, only the nicotine group, nicotine+AG490 group and the sham operation group were statistically significant compared with the ischemia group. *: $p<0.05$ versus the ischemia group.

Table 3 RT-PCR results: the relative expression of $a_{4-}$ and $\beta_{2} n A C h R$ mRNA in left thalamus of each group囚n=3区

\begin{tabular}{|lll|}
\hline Groups & $a_{4} \mathrm{nAChR}$ & $\beta_{2} \mathrm{nAChR}$ \\
\hline ischemia group & $0.51 \pm 0.04$ & $0.68 \pm 0.04$ \\
\hline nicotine group & $0.75 \pm 0.16^{\star}$ & $0.86 \pm 0.11^{*}$ \\
\hline nicotine + DH $\beta E$ & $0.56 \pm 0.14$ & $0.57 \pm 0.08$ \\
\hline DH $\beta E$ group & $0.50 \pm 0.02$ & $0.56 \pm 0.02$ \\
\hline nicotine + AG490 & $0.74 \pm 0.07^{\star}$ & $0.83 \pm 0.02^{\star}$ \\
\hline AG490 group & $0.51 \pm 0.08$ & $0.67 \pm 0.05$ \\
\hline sham operation group & $1.00 \pm 0.12^{\star}$ & $0.98 \pm 0.18^{\star}$ \\
\hline
\end{tabular}

Note: Relative expression means the mRNA expression of each index in different group relative to the normal rats which was the control group in RT-PCR. Each group was compared in pairs, only the nicotine, nicotine+AG490 and sham operation groups were statistically significant compared with the ischemia group. *: $p<0.05$ versus the ischemia group.

Table 4 Western blot results: the relative expression of protein $a_{4}$ and $\beta_{2} n A C h R$, IL-1 $\beta$, IL-6, JAK2, STAT3, p-JAK2, p-STAT3 in

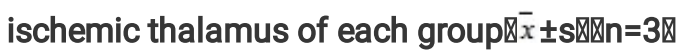

\begin{tabular}{|lllllllll|}
\hline Groups & $\mathrm{a}_{4} \mathrm{nAChR}$ & $\beta_{2} \mathrm{nAChR}$ & $\mathrm{IL}-1 \beta$ & $\mathrm{IL}-6$ & $\mathrm{JAK} 2$ & $\mathrm{p}-\mathrm{JAK} 2$ & STAT3 & p-STAT3 \\
\hline $\begin{array}{l}\text { ischemia } \\
\text { group }\end{array}$ & $1.44 \pm 0.05$ & $1.53 \pm 0.10$ & $0.85 \pm 0.03$ & $1.65 \pm 0.08$ & $1.44 \pm 0.04$ & $0.57 \pm 0.01$ & $1.32 \pm 0.01$ & $0.68 \pm 0.02$ \\
\hline $\begin{array}{l}\text { nicotine } \\
\text { group }\end{array}$ & $1.91 \pm 0.18^{*}$ & $2.05 \pm 0.12^{*}$ & $0.67 \pm 0.02^{*}$ & $1.17 \pm 0.03^{*}$ & $1.42 \pm 0.05$ & $0.95 \pm 0.03^{*}$ & $1.30 \pm 0.01$ & $1.12 \pm 0.02^{\star}$ \\
$\begin{array}{l}\text { nicotine } \\
\text { DH } \beta E\end{array}$ & $1.39 \pm 0.09$ & $1.47 \pm 0.11$ & $0.82 \pm 0.02$ & $1.64 \pm 0.05$ & $1.40 \pm 0.07$ & $0.61 \pm 0.07$ & $1.32 \pm 0.01$ & $0.68 \pm 0.05$ \\
$\begin{array}{l}\text { nicotine }+ \\
\text { AG490 }\end{array}$ & $1.88 \pm 0.12^{*}$ & $1.91 \pm 0.03^{*}$ & $0.81 \pm 0.01$ & $1.58 \pm 0.02$ & $1.41 \pm 0.06$ & $0.62 \pm 0.04$ & $1.35 \pm 0.05$ & $0.66 \pm 0.02$ \\
\hline $\begin{array}{l}\text { AG490 } \\
\text { group }\end{array}$ & $1.42 \pm 0.18$ & $1.51 \pm 0.10$ & $0.82 \pm 0.01$ & $1.61 \pm 0.03$ & $1.42 \pm 0.06$ & $0.60 \pm 0.01$ & $1.31 \pm 0.02$ & $0.63 \pm 0.02$ \\
\hline
\end{tabular}

Note: Relative expression was the protein expression of each index relative to $\beta$-actin. Each group was compared in pairs, only the nicotine group and nicotine+AG490 group were statistically significant compared with the ischemia group. *: $p<0.05$ versus the 


\section{Figures}

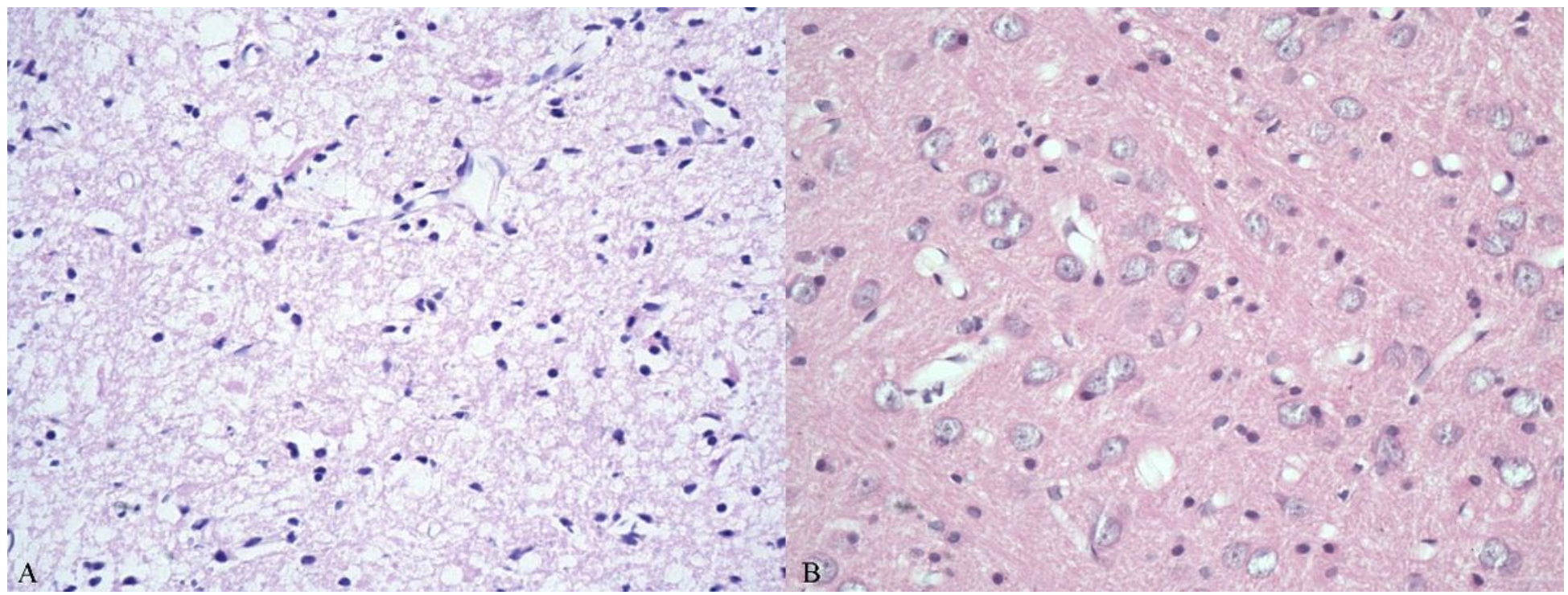

Figure 1

HE staining images of ischemic rat from the ischemia group $(A)$ and non-ischemic rat from the sham operation group (B). A showed ischemic tissue with many white cells and neurons and glial cells with necrosis or apoptosis. B showed normal tissue without necrotic cells. The ischemic model was successfully established in rat from the ischemia group.
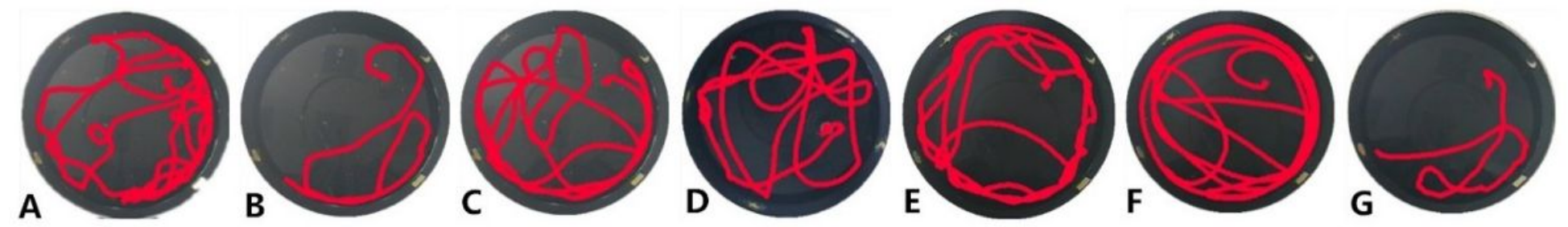

\section{Figure 2}

Evasion latency of Morris water maze navigation experiment in rats of each group Note: A-G represents the ischemia group, nicotine group, nicotine + DH $\beta E$ group, $D H \beta E$ group, nicotine + AG490 group, AG490 group and sham operation group. 


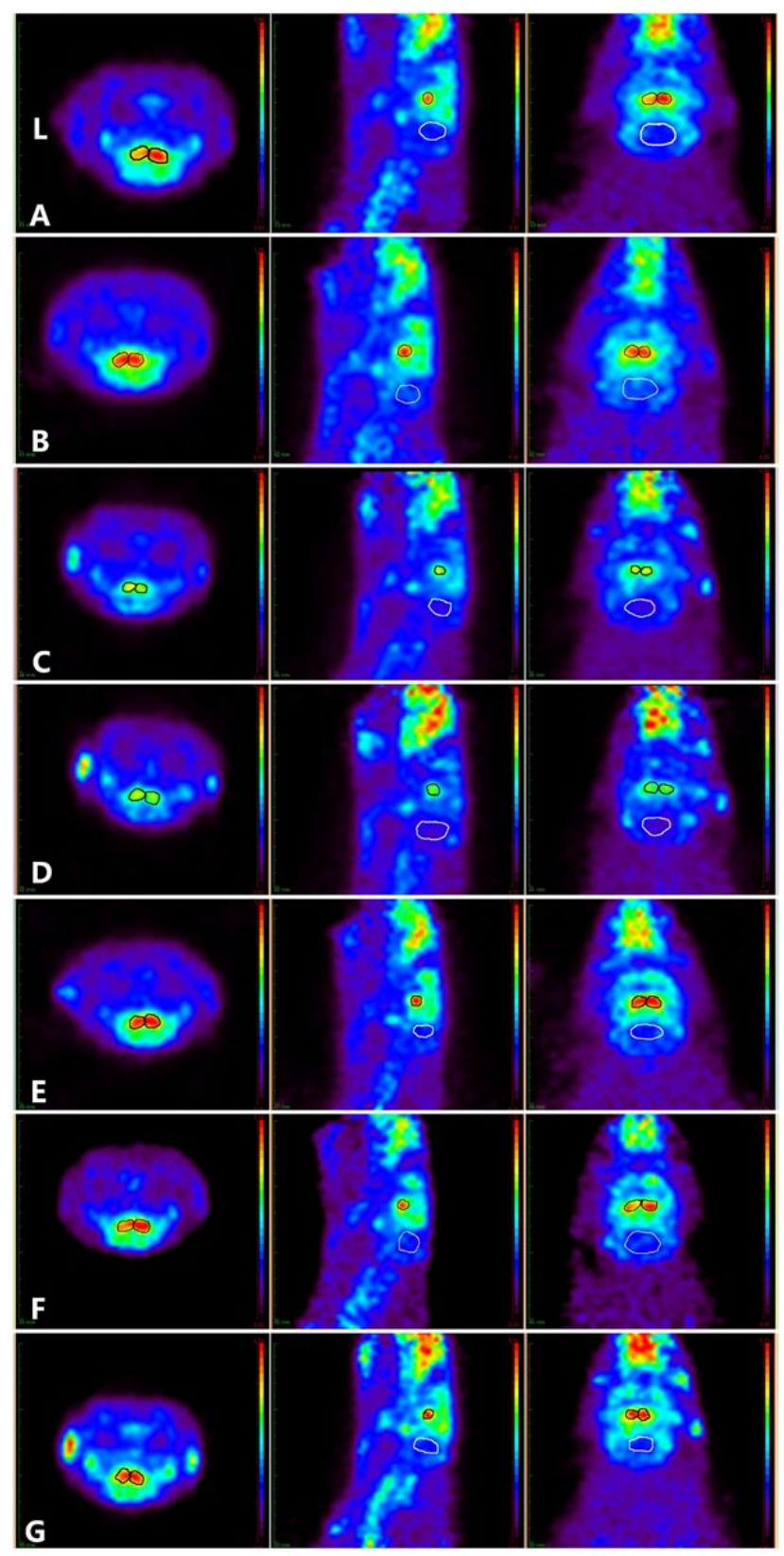

Figure 3

2-[18F]-A-85380 MicroPET imaging in 7 groups. Note: $A$ is the ischemia group. The lower uptake of tracer was observed in the left thalamus (black circle); $B$ is the nicotine group and $E$ is the nicotine+AG490 group, increased uptake of tracer was observed in the left thalamus; $C$ is the nicotine+DHBE group and $D$ is the $D H \beta E$ group. The uptake of tracer in bilateral thalamus and whole brain was poor; $F$ is the AG490 group. There was a decreased uptake of tracer in the left thalamus, similar as A; $G$ is the sham operation group. The distribution of tracer in bilateral thalamus was uniform and symmetrical. 


\section{$\alpha_{4} \mathrm{nAChR}$}
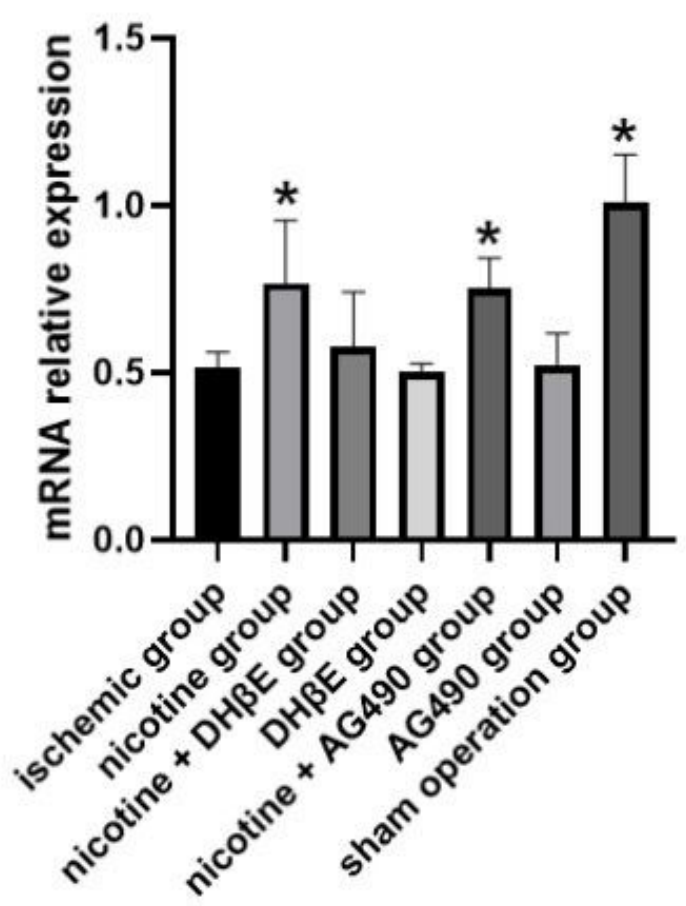

$\beta_{2} \mathrm{nAChR}$
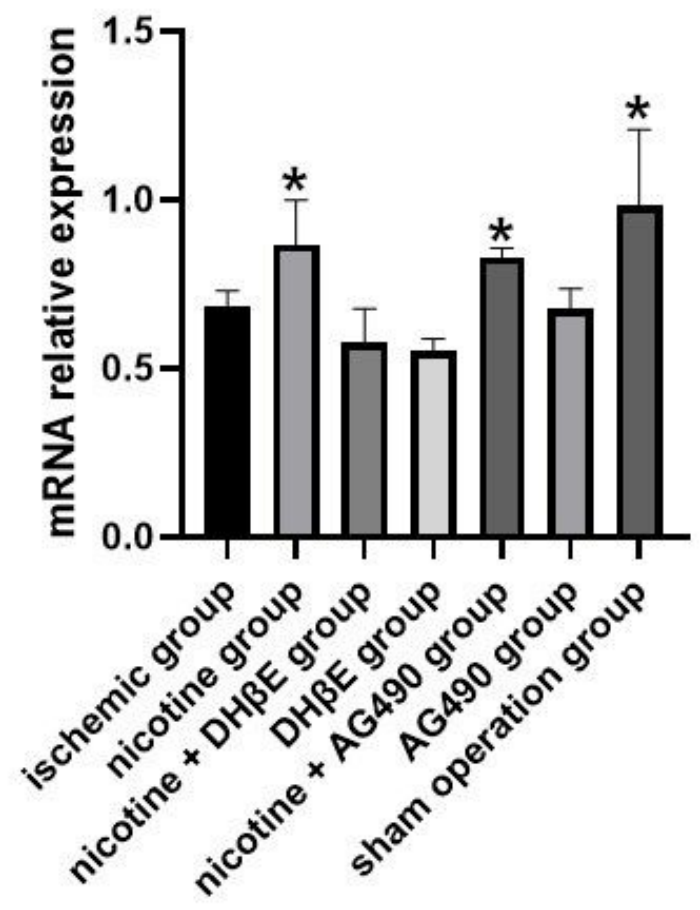

Figure 4

The relative expression of $a 4$ and $\beta 2 \mathrm{nAChR}$ mRNA in the left thalamus of each group. Note: Relative expression was the value of each index in the groups relative to the normal rats which was the control group in RT-PCR. *: $p<0.05$ versus the ischemia group 

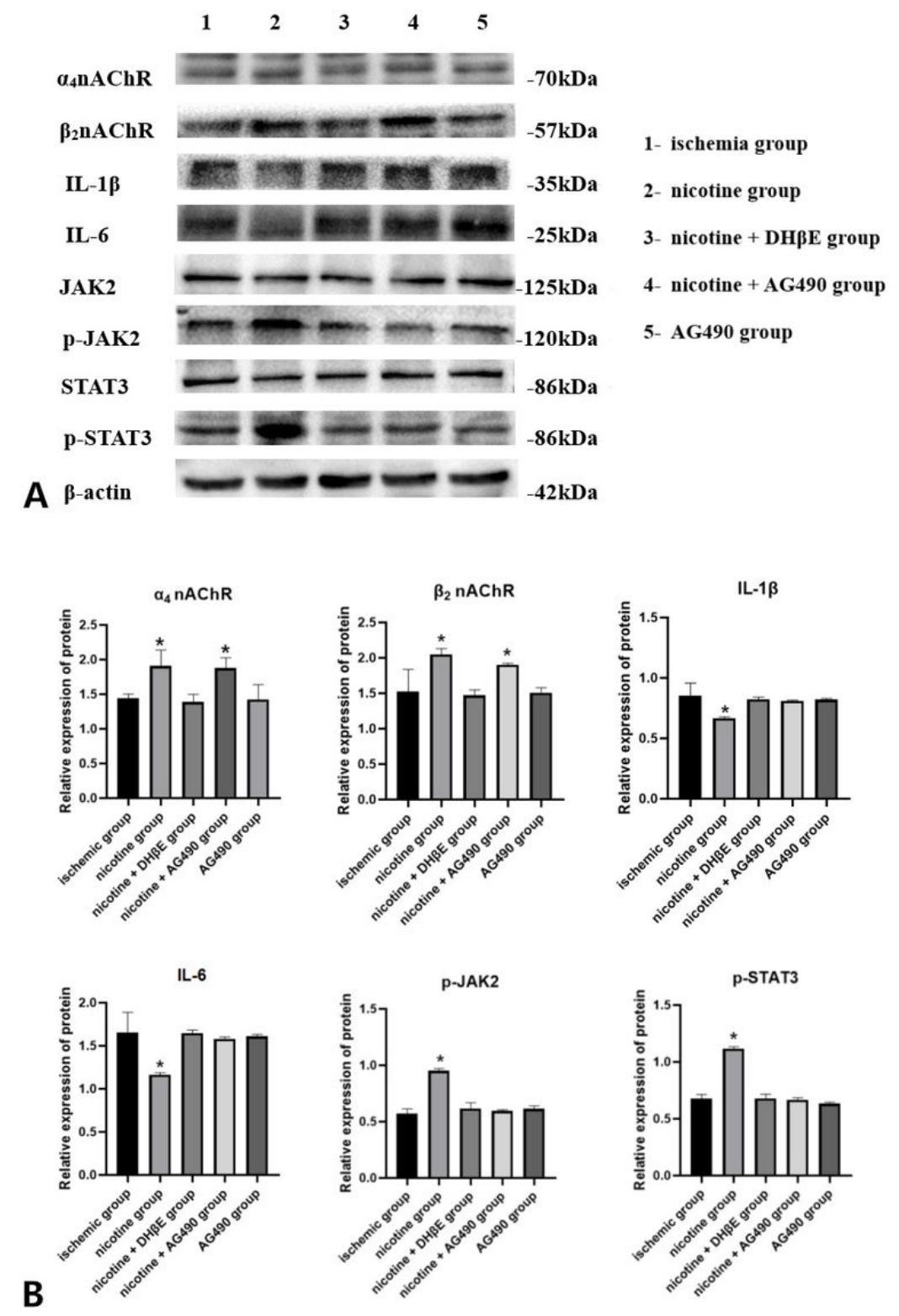

Figure 5

The results of Western Blot. A: The protein panel of $a 4$ and $\beta 2$ nAChR, IL-1 $\beta, I L-6, J A K 2, p-J A K 2$, STAT3, p-STAT3, $\beta$-actin in the left thalamus of each group. B: The relative expression of protein $\alpha 4$ and $\beta 2 n A C h R, I L-1 \beta, I L-6, p-J A K 2, p-S T A T 3$ in the left thalamus of each group. Note: Relative expression was the protein expression of each index relative to $\beta$-actin. *: $p<0.05$ versus the ischemia group. 